\title{
O CONTRATO NA PROPRIEDADE INTELECTUAL E O EQUILÍBRIO:
}

uma análise econômica da barganha e do equilíbrio

sob a perspectiva de diferentes tradições econômicas

\section{THE CONTRACT ON INTELLECTUAL PROPERTY AND THE EQUILIBRIUM:}

an economic analysis of bargain and equilibrium

under differents economics traditions perspective

\section{EL CONTRATO EN LA PROPIEDAD INTELECTUAL Y EQUILIBRIO:}

un análisis económico de la negociación y del equilibrio

bajo la perspectiva de diferentes tradiciones económicas

Edson Mota Valença Filho ${ }^{1}$

\author{
RECEBIBO 29/05/2019 \\ APROVADO 30/06/2019 \\ PUBLICADO 01/07/2019 \\ Editor Responsável: Carla Caldas \\ Método de Avaliação: Double Blind Review \\ E-ISSN: 2316-8080 \\ DOI: 10.16928
}

RESUMO

O artigo tem como objeto a análise econômica da Propriedade Intellectual como "remédio" a falha de mercado criativo e inventivo e o Direito Contratual. O objetivo geral do trabalho é análise econômica sob o prisma da Law and Economics, da Teoria dos Jogos e Escola Austríaca, dos contratos na propriedade intelectual.

Palavras-chave: Propriedade Intelectual. Contratos de Propriedade Intelectual. Análise Econômica do Direito.

ABSTRACT

The article has as object the economic analysis of Intellectual Property as "remedies" to the creative and inventive market failure and the Contract Law. In this sense, the general objective of this paper is the economic analysis of Intellectual Property and Contract Law under the perspective of Law and Economics, Game Theory and Austrian School.

Key word: Intellectual Property. Intellectual Property Contracts. Law and Economics.

\section{RESUMEN}

El artículo tiene como objeto el análisis económico de la Propiedad Intectual como "remedio" la falla de mercado creativo e inventivo y el Derecho contractual. El objetivo general del trabajo es análisis

\footnotetext{
${ }^{1}$ Advogado Empresarial na Mota Valença \& Campos Sociedade de Advogados (R. Quarenta e Oito, $\mathrm{n}^{\circ} 713$, Empresarial Aurino Duarte, sala 7, Aflitos, Recife/PE, CEP 52050-355), aluno do curso de pós-graduação lato sensu Direito Empresarial e Contratos do Centro Universitário de Brasília (UniCEUB/ICPD), Bacharel em Direito pela Faculdade Damas da Instrução Cristã (FADIC). E-mail: edsonfilho@motavalencacampos.adv.br; Perfil Orcid: $\quad \underline{\text { https://orcid.org/0000-0002-6595-381X; }}$ Currículo Lattes: http://lattes.cnpq.br/2069849159882597; $\quad$ Perfil Google Acadêmico:
} https://scholar.google.com.br/citations?user=pNSj3z0AAAAJ\&hl=pt-BR 
económico bajo el prisma de Law and Economics, de la Teoría de los Juegos y Escuela Austriaca, de los contratos en la propiedad intelectual.

Palabras-clave: Propiedad Intelectual. Contratos de Propiedad Intelectual. Análisis Económico del Derecho.

\section{INTRODUÇÃO}

A propriedade intelectual é um instituto jurídico de natureza peculiar em razão da sua proposta de proteger a atividade criativa - o direito de patentes, desenho industrial, autoral, marcas, indicação geográfica e concorrência desleal - através de uma "arquitetura" legal que incentive a competição justa e o equilíbrio no mercado. Os críticos dela, com razão, apontam a potencial nocividade desse instituto para a economia e o desenvolvimento tecnológicos, apresentando argumentos de caráter deontológicos, utilitários e casos em que a legislação promoveu exatamente oposto causando lesividade a inovações criativas ${ }^{2}$.

Sob o ponto de vista do empreendedor, o mencionado artificio jurídico é o custo legal para: a) manter, por um certo período de tempo, a exploração monopolística do fruto criativo; b) protegerse de um terceiro, que de má-fé ou por coincidência, decida usufruir do mecanismo legal ${ }^{3}$; c) impedilo de empreender naquele determinado segmento comercial; e, por fim, d) uma estratégia de determinar o valor de seu empreendimento e agregar poder de barganha. Essas 4 (quatro) conjecturas representam as principais consequências da propriedade intelectual no processo de mercado.

Nessa toada, há uma clara tensão em virtude da intervenção, por meio da ferramenta do Direito, no mercado da criatividade que, paradoxalmente, pode ser um empecilho (incentivo negativo), até mesmo uma barreira instransponível, à atividade criativa. Em tal cenário, o instituto imemoriável do contrato funciona com a dual função de mitigar e garantir a proteção da propriedade intelectual.

Ante o exposto, no mundo jurídico as principais formas de garantir o Direito na época contemporânea são através da litigação no Poder Judiciário - ou em um Juízo Arbitral, quando houver a celebração de uma convenção de arbitragem válida ${ }^{4}$ - e por meio de uma relação negocial que estipule obrigações a ambas as partes. Consequentemente, o contrato pode ser entendido como ferramenta subsidiária apta a promover o processo de mercado - corrigindo a falha de mercado -,

\footnotetext{
2 Tais críticas concentram seus argumentos no sistema de patentes e nos direitos autorais, todavia há quem aproveite o esbouço teórico argumentativo para expandir em face das marcas, indicações geográficas, desenho industrial e, até mesmo, a legislação de concorrência desleal.

${ }^{3}$ Esse fenômeno ocorre em virtude da regra first to fill que garante a proteção daquela tecnologia - ou design tecnológico -, expressão ou signo para o primeiro que a registrar no órgão competente.

${ }^{4}$ A convenção de arbitragem pode ser uma cláusula compromissória, presente no instrumento contratual original ou em um aditivo, ou um compromisso arbitral celebrado quando já há a presença de uma controvérsia.
} 
garantir a eficácia da lei de propriedade intelectual além de prevenir abusos dos titulares desse direito na sua atividade empresarial e/ou litigância desnecessária.

O Direito Contratual sob o prisma da tradição econômica neoclássica tem como função criar o equilíbrio de mercado ${ }^{5}$ em uma escala macroeconômica ${ }^{6}$, todavia, os avanços teóricos, creditados aos estudiosos da Teoria do Jogos, adicionam a figura do equilíbrio entre as partes em um contrato sob uma abordagem microeconômica ${ }^{7}$. Em outras palavras, o designo privado e as normas, em conjunto, podem alcançar a mens legis quando existente incentivo suficiente possibilitando a concretização do direito à propriedade intelectual.

Nesse diapasão, a análise econômica do Direito popularizada na segunda metade do Século XX, com os estudos de Ronald Coase, mais tarde é influenciada pelos avanços da Teoria dos Jogos adotando análises semi dinâmicas dos fenômenos econômicos, estudando as escolhas dos agentes, dando um novo "fôlego" aos economistas neoclássicos ${ }^{8}$. Todavia, apesar do avanço significativo do arcabouço teórico, há objeções quanto aos resquícios da teoria do equilíbrio e sua (im)possiblidade de ser concretizada ante as críticas pertencentes a Escola Austríaca de Economia, sendo oportuno o seguinte questionamento: o mecanismo de propriedade intelectual pode levar ao equilíbrio entre as partes e ao mercado?

Em resposta a essa indagação, a atividade empresarial em um cenário em que há incerteza, divergência de objetivos, assimetria de conhecimento e recurso entre os participantes, necessita de uma análise bem embasada na tríade: ação, conhecimento e tempo; A prima facie, o equilíbrio entre criadores e copiadores é dificilmente encontrado pelo o método heterocompositivo, em virtude do custo legal, o prazo e a qualidade incerta de uma decisão. Todavia, é possível corrigir e otimizar o instituto com o auxílio do Direito Contratual ao ponto de garantir ao mecanismo de propriedade intelectual uma maior eficiência e um potencial maior ao equilíbrio designado pela mens legis. Nesse sentido, a lei contratual desempenha papel subsidiário as de propriedade intelectual na função de proteger os direitos dos criativos em alguns determinados casos, na escala microeconômica, e como forma de prevenção de riscos judiciais e incentivar o mercado, em escala macroeconômica.

\footnotetext{
${ }^{5}$ A teoria do equilíbrio refere a hipótese do cenário em que os preços dos bens são determinados unicamente pela oferta e demanda, um regime de concorrência perfeita em que as forças do mercado estão em iguais proporções e, portanto, há estabilidade e constância.

${ }^{6}$ FARBER, Daniel A. Contract Law and Modern Economic Theory. Northwestern University Law Review, [s.1.], v. 78, n. 2, pp. 303-339, jan. 1983, p. 311-312.

7 PICKER, Randal C. An introduction to game theory and the law. Coase-Sandor Institute for Law \& Economics, [s.1.], n. 22, pp. 2-20, 1994.

${ }^{8}$ FOSS, Nicolai. Austrian economics and Game Theory: a stocktaking and an evaluation. The Review of Austrian Economics, [s.1.], v. 13, issue 1, pp-41-58, feb. 2000, p. 41-42.
}

PIDCC, Aracaju/Se, Ano VIII, Volume 13 no 02, p.146 a 174 Jul/2019 | www.pidcc.com.br 
Isto posto, o objetivo geral desse artigo é analisar economicamente o Direito Intelectual e a aplicação do Direito Contratual através da análise econômica de 3 (três) tradições de escolas econômicas: neoclássica, teoria dos jogos e austríaca. A pesquisa é do tipo bibliográfica e utiliza o método hipotético dedutivo.

Por sua vez, os objetivos específicos da obra, que compõe os tópicos seguintes na ordem apresentada, são: a) estudar a propriedade intelectual e o contrato como meio de resguardar o direito à propriedade intelectual; b) analisar os fundamentos da teoria dos jogos aplicada aos contratos de propriedade intelectual e a teoria do equilíbrio; e, por fim, c) avaliar os desdobramentos argumentativos sob o prisma da Escola Austríaca de Economia.

O primeiro item desse trabalho será dedicado a estudar o instituto da propriedade intelectual, apontando as diferentes justificativas - deontológicas e utilitárias - usadas na confecção desse direito, em tempos passados e atualmente, além de dá ênfase ao uso dos contratos como ferramenta de eficácia desse direito. Em seguida, empregado os conceitos e fundamentos da Análise Econômica do Direito para, na sequência, analisar o instituto da propriedade intelectual aplicando o modelo de jogo cooperativo, baseado no dilema dos prisioneiros, e o subterfugio dos contratos como mecanismo de eficácia. Por fim, será feita uma apresentação da tríade básica da Escola Austríaca, apontando as diferenças entre a abordagem da Análise Econômica do Direito e a teoria dos jogos, para avaliar os argumentos construídos para a propriedade intelectual.

\section{A PROPRIEDADE INTELECTUAL E OS CONTRATOS: O MECANISMO DE PROTEÇÃO A CRIATIVIDADE}

A defesa do direito à propriedade intelectual tem como sua principal intenção a tutela jurídica protetiva aos atos e processos criativos por meio da construção de um aparato capaz de dotar as expressões - trabalhos artísticos ou científicos, inovações e novas tecnologias -, os signos identificadores dos agentes e dos $\operatorname{produtos}^{9}$ com o caráter de exclusividade, durante um lapso temporário, do uso, usufruto e disposição ${ }^{10}$. Por essa característica o instituto jurídico é qualificado como uma variação do direito de propriedade.

\footnotetext{
${ }^{9} \mathrm{O}$ direito à propriedade intelectual subdivide-se em Direitos Autorais, que engloba o direito conexo e do software (Lei $n^{\circ}$ 9.609/1998), regulados pelas Lei $n^{\circ}$ 9.610/1998 e Propriedade Industrial, a qual por sua vez abrange as patentes, modelos de utilidade, desenho industrial, marcas, indicações geográficas e a concorrência desleal, dispostos na Lei no 9.276/1996.

${ }^{10}$ Consoante o artigo 1.228 do Código Civil de 2002, ipsis litteris: "o proprietário tem a faculdade de usar, gozar e dispor da coisa, e o direito de reavê-la do poder de quem quer que injustamente a possua ou detenha".
} 
A finalidade das leis de propriedade intelectual é a criação de uma "arquitetura" jurídica que instaure mercado no qual existam incentivos ao desenvolvimento de técnicas e expressões artísticas ou científicas. Em outras palavras, é a implementação de um sistema que compense aos autores e inventores pelo investimento dos seus recursos no exercício da atividade intelectual, além de aumentar os custos do empreendimento dos free-riders ${ }^{11}$.

Sob esse entendimento, é consequência lógica à supracitada teleologia legal a promoção do equilíbrio de mercado em relação ao fruto da intelectualidade através do aumento artificial dos custos aos imitadores por um determinado período de tempo ${ }^{12}$. Dessa forma, o investimento na pesquisa, desenvolvimento de novas tecnologias e obras não serão ônus insuportáveis, ou debilitantes, ao inventor/autor na exploração comercial.

Nesse sentido, o instituto jurídico da propriedade intelectual desempenha a função macroeconômica de equilíbrio do mercado e de política de incentivo a inovação. Todavia, é possível apontar contradições inerentes ao referido sistema que restringem a concorrência e podem levar ao desequilíbrio ${ }^{13}$ fomentando carteis e monopólios ${ }^{14}$. Consequentemente, essa tecnologia legal tem a difícil missão de conciliar a natureza ambígua de delegar a exploração comercial exclusiva e preservar a competição mercadológica ${ }^{15}$.

No Brasil, o direito à propriedade intelectual foi esculpido nos incisos XXVII ${ }^{16}$ e XXIX ${ }^{17}$ do artigo $5^{\circ}$ da Constituição Federal de 1998 (CF/88) o consagrando como direito e garantia individual,

${ }^{11} \mathrm{O}$ termo é dirigido aqueles que vão de carona nos benefícios gerados pelas atividades de outrem sem pagar. No contexto da propriedade intelectual, os "caroneiros" são aqueles que vão imitar os inventores e autores participando do processo de mercado sem o ônus do investimento e desenvolvimento do exercício criativo. TIMM, Luciano Benetti; CAOVILLA, Renato. As teorias rivais sobre a propriedade intelectual no Brasil. Berkeley: Berkley Program in Law and Economics, 2009, p. 7. Disponível em: $<$ https://escholarship.org/uc/item/3fs9d0m3\#main. Acesso em: 12 out 2018.

12 BESEN, Stanley M.; RASKIND, Leo J. An introduction to the law and economics of intellectual property. Journal of Economic Perspectives, [s.L.], v. 5, no 1, p.3-27, winter 1991, p. 5.

${ }^{13}$ MELLO, Maria Tereza Leopardi. Propriedade Intelectual e Concorrência. Revista Brasileira de Inovação, Rio de Janeiro, v. 8, no 2, p. 371-402, julho/dezembro 2009, p. 373.

14 LANDES, William M.; POSNER, Richard A. The political economy of intellectual property law. Washington D.C.: AEI-Brookings Joint Center for Regulatory Studies, 2004, p. 12.

15 "a slavish application of the concept of property as it has been developed for material things has done a great deal to foster the growth of monopoly and that here drastic reforms may be required if competition is to be made to work. In the field of industrial patents in particular we shall have seriously to examine whether the award of a monopoly privilege is really the most appropriate and effective form of reward for the kind of risk-bearing which investment in scientific research involves". HAYEK, Friedrich A. Individualism \& Economic Order. 3 ed. Chicago: The University of Chicago Press, 1958, p.114.

${ }^{16}$ Nesse sentido, o artigo 27, (2), da Declaração Universal dos Direitos do Humanos de 1948 dispõe como direito universal inerente ao homem os direitos de morais e de exploração comercial sobre obras cientificas literais ou artísticas.

17 “a lei assegurará aos autores de inventos industriais privilégio temporário para sua utilização, bem como proteção às criações industriais, à propriedade das marcas, aos nomes de empresas e a outros signos distintivos, tendo em vista o interesse social e o desenvolvimento tecnológico e econômico do País” (grifos acrescidos). 
coadunando com a noção de amplitude do conceito constitucional de propriedade ${ }^{18}$. Ademais, o artigo 60, §4 $4^{\circ}, \mathrm{IV}$, da $\mathrm{CF} / 88$, o dá status de cláusula pétrea ${ }^{19}$ abonando limites materiais ao Poder Reformador ao modificar os dispositivos que explicita ou implicitamente tentem abolir ou diminuir a eficácia desse direito.

Adiante, outra característica peculiar ao instituto de proteção às atividades criativas é seu caráter internacionalista representado pela tentativa dos Estados-Nações em celebrar acordos, multilaterais e bilaterais, que regulem as proteções do direito autoral e industrial no comércio internacional e atuação das empresas estrangeiras no mercado doméstico. Essa finalidade materializa organismos e mecanismos de solução de controvérsias internacionais ${ }^{20}$ para desenvolver a uniformidade do direito à propriedade intelectual entre os países signatários ${ }^{21}$.

O fenômeno da internacionalização das regras desse instituto é no mínimo estranha ante a justificativa histórica das patentes e é um “divisor de águas” por significar a aceitação como direito individual. Em épocas remotas, as patentes eram indissociáveis de privilégios conferidos pelas autoridades estatais como forma de promover o desenvolvimento ${ }^{22}$ ou destinados ao controle de informações e do comércio delas ${ }^{23}$.

\subsection{A propriedade intelectual um direito de propriedade ou um privilégio legal?}

As raízes históricas do Direito de Propriedade Intelectual não fazem distinção entre os direitos autorais ou propriedade industriais ${ }^{24}$. O termo patente era usado quase como sinônimo de privilégio

\footnotetext{
${ }^{18}$ BASSO, Maristela. A tutela constitucional da propriedade intelectual na Carta de 1988: avanço indiscutível. Revista de Informação Legislativa, Brasília, v. 45, n. 179, p. 39-41, jul./set. 2008, p.40.

${ }^{19}$ SARLET, Ingo Wolfgang. Os direitos fundamentais sociais como "cláusulas pétreas". Caderno de Direito, Piracicaba, v. 3, n. 5, p.78-97, jul./dez. 2003, p. 80.

${ }^{20} \mathrm{O}$ artigo 64 do Acordo sobre Aspectos do Direito de Propriedade Intlectual Relacionado ao Comércio (ADPIC) ou Agreement on Trade-Related Aspects of Intellectual Property Rights (TRIP) elege o sistema de solução de controvérsias da Organização Mundial de Comércio (OMC), para versar sobre as disputas em relação a Propriedade Intelectual, substituindo o recurso facultativo a Corte Internacional de Justiça prevista na Convenção de Paris, versão de Estocolmo, 1967, artigo 28. PIMENTEL, Luiz Otávio. O acordo sobre os aspectos dos direitos de propriedade intelectual relacionados com o comércio. Seqüência: Estudos Jurídicos e Políticos, Florianópolis, p. 167-196, jan. 2002, p.190. ISSN 2177-7055. Disponível em: $<$ https://periodicos.ufsc.br/index.php/sequencia/article/view/15338. Acesso em: 08 set. 2018.

${ }^{21}$ Consoante os artigos $3^{\circ}$ e $4^{\circ}$ da Convenção de Estocolmo 1967, ver mais em: PIMENTEL, Luiz Otávio. O acordo sobre os aspectos dos direitos de propriedade intelectual relacionados com o comércio. Seqüência: Estudos Jurídicos e Políticos, Florianópolis, p. 167-196, jan. 2002, p.169. ISSN 2177-7055. Disponível em: $<$ https://periodicos.ufsc.br/index.php/sequencia/article/view/15338. Acesso em: 08 set. 2018.

${ }^{22}$ KOSTYLO, Joanna. From gunpowder to print: the common origins of copyright and patent. In: DEAZLEY, Ronan; KRETSCHMER, Martin; BENTLY, Lionel. Privilege and Property: Essays on the history of copyright.Cambridge OpenBook Publishers: 2010, p.23-25.

${ }^{23}$ ZANINI. Leonardo Estevam de Assis. O Estatuto da Rainha Ana: estudos em comemoração dos 300 anos da primeira lei de copyright. Revista do Tribunal Regional Federal da $1^{\text {a }}$ Região, Brasília, v. 22, n. 9, ou. 2010.

${ }^{24}$ KOSTYLO, Joanna. From gunpowder to print: the common origins of copyright and patent. In: DEAZLEY, Ronan; KRETSCHMER, Martin; BENTLY, Lionel. Privilege and Property: Essays on the history of copyright.Cambridge OpenBook Publishers: 2010, p.23-25.
} 
vinculado a expectativa da autoridade estatal em desenvolver o comércio doméstico. No Brasil, o instituto foi implantado pela primeira vez com o Alvará de Dom João VI em 1806 como parte do plano de desenvolver o país ${ }^{25}$.

Outrossim, além das justificativas utilitárias, a concessão do controle sobre a expressão dos autores e inventores também possuíam argumentos de cunho éticos-morais ${ }^{26}$. Todavia, somente recentemente esses direitos ganharam o status jurídico de propriedade ${ }^{27}$ ganhando força com os estudos da Análise Econômica do Direito ${ }^{28}$ e, no mundo, com a criação do organismo internacional da Organização Mundial de Propriedade Intelectual (OMPI).

A adoção do mecanismo de proteção legal similar a propriedade para atividade criativa enfrenta alguns desafios ante a delimitação de fronteiras a um objeto abstrato em relação a terceiros. Isto é, o direito de propriedade tradicional possui limites claros quanto ao objeto protegido, daí sua natureza erga omnes. Todavia, na propriedade intelectual essa tarefa é mais árdua.

A adoção do mecanismo de proteção legal similar a propriedade para defender os interesses comerciais dos autores e inventores exige respostas há alguns desafios inerentes a abstração do objeto desse direito. Isto é, em virtude do caráter incorpóreo da expressão criativa há dificuldades em estabelecer ligações naturais entre o Direito Intelectual e o Real.

Sob o ponto de vista legal, no direito à propriedade, em virtude da capacidade natural de apropriação do objeto, há a delimitação clara do que está sendo privatizado e, por essa razão, há maior facilidade em distribuir as obrigações negativas aos terceiros. Consequentemente, a essência desse direito é o controle monopolístico legítimo e justo sobre um item dotado de escassez ${ }^{29}$, sendo a última característica o verdadeiro ponto de intersecção entre o prisma jurídico e o econômico, é irrelevante a natureza material do bem desde que este não implique na perpetuação de controvérsias ${ }^{30}$.

\footnotetext{
${ }^{25}$ CABELLO, Andrea Felippe; PÓBOA, Luciano Martins Costa. Análise econômica da primeira Lei de Patenttes brasileiras. Estud. Econ., São Paulo, v. 46, n. 4, p. 870-907, dec. 2016.

${ }^{26}$ DEAZLEY, Ronan; KRETSCHMER, Martin; BENTLY, Lionel. Privilege and Property: Essays on the history of copyright.Cambridge OpenBook Publishers: 2010, p.4.

${ }^{27}$ LEMLEY, Mark A. Property, Intellectual Property, and Free Riding. Texas Law Review, [s.1.], vol. 83, issue 291, 2004, p.4.

${ }^{28}$ LEMLEY, Mark A. Property, Intellectual Property, and Free Riding. Texas Law Review, [s.1.], vol. 83, issue 291, 2004, p.8.

29 "To develop the concept of property, it is necessary for goods to be scarce, so that conflicts over the use of these goods can possibly arise. It is the function of property rights to avoid such possible clashes over the use of scarce resources by assigning rights of exclusive ownership. Property is thus a normative concept: a concept designed to make a conflict-free interaction possible by stipulating mutually binding rules of conduct (norms) regarding scarce resources". HOPPE, Hans-Hermann. A theory of socialism and capitalism. Boston: Kluwer Academic Publishers, 1989, p. 18.

30 "[O]nly because scarcity exists is there even a problem of formulating moral laws; insofar as goods are superabundant ("free" goods), no conflict over the use of goods is possible and no action-coordination is needed. Hence, it follows that any ethic, correctly conceived, must be formulated as a theory of property, i.e., a theory of the assignment of rights of exclusive control over scarce means. Because only then does it become possible to
} 
Nesse diapasão, a tecnologia legal que dá aos inventores e autores o controle exclusivo sobre seus inventos e expressões cria, na verdade, uma "escassez" artificial através do mecanismo de proteção $^{31}$. De fato, em termos práticos, é uma flexibilização do direito de propriedade tradicional uma vez que rateia entre os titulares do direito de propriedade intelectual o controle parcial do direito de propriedade de outrem proibindo a eles a cópia ou imitação ${ }^{32}$.

Isto exposto, apesar da ligação histórica do direito à propriedade intelectual com leis de responsabilidade por ato ilícito ${ }^{33}$, de $\operatorname{subsídios}^{34}$ e competição $^{35}$ seu status como direito real é categoricamente ligado a legislação, sendo uma espécie de "propriedade estatutária"36, estando sujeita as mesmas limitações da propriedade, previstas no artigo $5^{\circ}$, XXIII, da CF/88, o atendimento a função social.

Em decorrência desse recurso de contrapeso, no ordenamento jurídico brasileiro, a figura da proteção da expressão dos autores e inventores por meio de alguns institutos do Direito Real não são tão contraditórios quanto em países cuja a tradição legal assinala um caráter mais absoluto ao direito à propriedade. A função social da propriedade pode ser dita como causa genética da propriedade intelectual e a ferramenta ideal para balancear os abusos advindos da exploração de patentes, por

avoid otherwise inescapable and unresolvable conflict". HOPPE, Hans-Hermann. A theory of socialism and capitalism. Boston: Kluwer Academic Publishers, 1989, p. 235.

31 "It is a peculiarity of Property rights in patentes (and copyrights) that they do not arise out of the scarcity of the objects which become approprieated. They are not a consequence of scarcity. They are the deliberate creation of statute law, and, whereas in general the institution of private property makes for the preservation of scarce goods, tending... to led us "to make the most of them,", property rights in patents and copyrights make possible the creation of a scarcity of the products appropriated which could not otherwise be maintained". PLANT, Arnold. The economic theory concerning patents for inventions. In: PLANT, Arnold. Selected economic essays and addresses. London: Routledge \& Kegan Paul, 1974, p.36.

32 “(...) IP rights gibe to pattern-creators partial rights of control - ownership - over the tangible property of everyone else. The pattern-creator has partial ownership of others's property, by virtue of his IP right, because he can prohibit them from performing certain actions with their own property. Author X, for example, can prohibit a third party, Y, from inscribing a certain pattern of words on Y's own blank pages with Y's own ink.(..) IP rights change the status quo by redistributing property from individuals of one class (tangible-property owners) to individuals of another (authors and inventors). Prima facie, therefore, IP law trespasses against or "takes" the property of property owners, by transferring partial ownership to authors and inventors. It is this invasion and redistribution of property that must be justified in order for IP rights to be valid.", KINSELLA, Stephan Kinsella. Against Intellectual Property. Journal of Libertarian Studies, v. 15, n. 2, pp. 1-55, 2001, p.25.

33 “(...) In another era we treate intellectual Property as a species of business tort, lodging trademarks and trade secrets in the Restatement of Tort and including chapters on copyright and patent in tort casebooks". LEMLEY, Mark A. Property, Intellectual Property, and Free Riding. Texas Law Review, [s.l.], vol. 83, issue 291, 2004, p. 52.

${ }^{34}$ BELL, Tom. Author's welfare: copyright as a statutory mechanism for redistributing rights. Brooklyn Law Review, [s.L.], v. 69, issue 1, pp 229-280, 2003, p. 236-237.

${ }^{35}$ LEMLEY, Mark A. Property, Intellectual Property, and Free Riding. Texas Law Review, [s.l.], vol. 83, issue 291, 2004, p. 53.

${ }^{36}$ Nesse sentido, em 1980 a Suprema Corte do Canadá entendeu os direitos autorais, nas palavras do Justice Estey, como uma lei estatuária, em virtude das características de direitos reais e de responsabilização, ipsis litteris: "Copyright law is neither tort law nor property law in classification, but is statutory law. It neither cuts across existing rights in property or conduct nor falls between rights and obligations heretofore existing in the common law. Copyright legislation simply creates rights and obligations upon the terms and in the circumstances set out in the statute". Compo Co. Ltd. v. Blue Crest Music et al., [1980] 1 SCR 357, 1979 CanLII 6 (SCC). 
exemplo, o que por consequência tem o potencial de criar incertezas quanto à qualidade das decisões heterocompositivas.

Entretanto, o principal fator para a proteção dos direitos de propriedade intelectual não está no mecanismo judicial disponível aos seus titulares para uma litigação, mas, sim, na liberalidade desse sistema em permitir a celebração de contratos de licenciamento das expressões e patentes. Uma vez que a principal justificativa é a correção da falha de mercado inerente a atividade criativa.

\subsection{O método autocompositivo como meio de eficácia do direito à propriedade intelectual.}

A existência de instituições sociais que disponibilizem meio heterocompositivo como solução de controvérsias, positivando obrigações e deveres, é sem dúvida algo necessário para o desenvolvimento de uma atividade econômica seja ela qual for. Todavia, na dinâmica do mercado, os modelos de negócio e preferências subjetivas dos agentes não podem ser previstos com exatidão pelas leis e regulamentos.

Nesse cenário, típico da vida cívica, o Estado tem como função, na aplicação desses institutos, de garantir a ordem, agindo tal qual o idealizado Night-watchman State ${ }^{37}$. Há, então, a exigência de normas com hipóteses mais amplas que contrabalanceiem a liberdade e a segurança necessária para o desempenho das atividades civis, vis-à-vis, a tentativa de implementar normas mais restritas consequentemente levaria ao totalitarismo, a inibição da vida civil e a impossibilidade da existência de qualquer atividade econômica.

O negócio jurídico e o Direito Contratual são os institutos essenciais para a possibilidade de uma sociedade permitindo que os titulares de direitos barganhem obrigações entre $\mathrm{si}^{38}$ e estipulem regras especificas para o caso concreto ${ }^{39}$ de acordo com suas vontades e a pertinência da situação

\footnotetext{
37 "One must be in a position to compel the person who will not respect the lives, health, personal freedom, or private property of others to acquiesce in the rules of life in society. This is the function that the liberal doctrine assigns to the state: the protection of property, liberty, and peace. The German socialist, Ferdinand Lassalle, tried to make the conception of a government limited exclusively to this sphere appear ridiculous by calling the state constituted on the basis of liberal principles the "night-watchman state". MISES, Ludwig von. Liberalism: in the classical tradition. 3 ed. Auborn: Mises Institute, 2000, p. 37. Disponível em: <https://misesmedia.s3.amazonaws.com/Liberalism\%20In\%20the $\% 20$ Classical\%20Tradition_3.pdf?file $=1 \&$ type $=$ documen . Acesso em: 13 set 2018.

${ }^{38}$ REALE, Miguel. Lições Preliminares de direito. 27. ed. São Paulo: Saraiva, 2004, p. 208-209.

$39 \mathrm{O}$ princípio da liberdade contratual estabelece aos agentes a permissão de estipular regras específicas e propícias para dirimir as obrigações objeto do acordo, em outras palavras, é a liberdade de prevê as hipóteses e as consequências ao caso concreto. Tal princípio, não é distinto da liberdade de contratar a qual está ligada a faculdade de escolher as partes contraentes e de contratar.
} 
fática. Tal instituto, desempenha função subsidiária às leis ${ }^{40} \mathrm{e}$ diminuindo o impacto das limitações inerentes aos homens ao legislar.

Sob esses fundamentos, é necessário que o Direito, como ferramenta de controle social ${ }^{41}$, permita o uso subsidiário dos meios da autotutela, autocomposição e heterocomposição, para solução e, até mesmo, antecipação de controvérsias. Por sua vez, a figura dos negócios jurídicos bilaterais e multilaterais estão bem ligados aos métodos autocompositivo sendo seu resultado os contratos ${ }^{42}$.

Nesse diapasão, os contratos de propriedade intelectual são ferramentas necessárias a eficácia do Direito de Propriedade Intelectual. A negação da liberdade dos titulares desses direitos tornaria o mecanismo de proteção à expressão intelectual deficitário, impediria a exploração econômica de forma eficiente e, em última instância, condenaria o mercado a um regime monopolístico sobre uma tecnologia ou expressão por 1 (um) único empreendedor.

Dessa maneira, o contrato, além de permitir a eficácia do Direito de Propriedade Intelectual, previne o uso abusivo e os desperdícios de recursos inerentes aos regimes monopolísticos.

\section{A ANÁLISE ECONÔMICA DA PROPRIEDADE INTELECTUAL, O DIREITO CONTRATUAL E A TEORIA DOS JOGOS}

A Análise Econômica do Direito é uma nova escola que concentra seus estudos no impacto que as leis provocam nas escolhas dos indivíduos ${ }^{43}$. Esse segmento doutrinário tem como seu

\footnotetext{
40 "É significativo o fato de que a autonomia privada é tida como sendo pedra angular do sistema civilístico inserido em contexto econômico-político próprio. A análise da autonomia privada, cuja expressão é autonomia da vontade, está diretamente vinculada ao espaço que o universo jurídico reserva aos particulares para disporem sobre seus interesses. Em verdade, a autonomia privada tem um reconhecimento da ordem jurídica, na medida em que a própria lei confere explicitamente o espaço em branco para que os particulares o preencham. Esse reconhecimento decorre da aplicação de um critério de exclusão, pois os particulares atuam nos espaços permitidos, isto é, não vedados pela ordem jurídica". FACHIN, Luiz Edson. Novo conceito de ato e negócio jurídico. Curitiba: Educa, Scientia et Labor, 1988, p. 54.

${ }^{41}$ SÁ FILHO, Fábio Menezes de. Análise da Admissibilidade da Resolução de Conflitos Individuais Afetos ao Direito Laboral Desportivo pela Arbitragem no Brasil. In: Melo Filho, Álvaro; SÁ FILHO, Fábio Menezes de; SOUZA NETO, Fernando Tasso de; RAMOS, Rafael Texeira (Coord). Direito do Trabalho Desportivo Homenagem ao Professor Albino Mendes Baptista. Recife: Quartier Latin, 2012, p. 109.

42 "São três as formas de autocomposição (as quais sobrevivem até hoje com referência aos interesses disponíveis): a) desistência (renúncia à pretensão); b) submissão (renúncia à resistência oferecida à pretensão); c) transação (concessões recíprocas). Todas essas soluções têm em comum a circunstância de serem parciais no sentido de que dependem da vontade e da atividade de uma ou de ambas as partes envolvidas". CINTRA, Antônio Carlos de Araújo; GRINOVER, Ada Pellegrini; DINAMARCO, Cândido Rangel. Teoria geral do processo. 29. ed. São Paulo: Malheiros, 2007, p. 29.

43 "Economics provided a scientific theory to predict the effects of legal sanctions on behavior. To economists, sanctions look like prices, and presumably, people respond to these sanctions much as they respond to prices. People respond to higher prices by consuming less of the more expensive good; presumably, people also respond to more severe legal sanctions by doing less of the sanctioned activity. Economics has mathematically precise theories (price theory and game theory) and empirically sound methods (statistics and econometrics) for analyzing the effects of the implicit prices that laws attach to behavior". COOTER, Robert; ULEN, Thomas.
} 
principal objetivo propor a reforma de sistemas legais, por meio de abolição, promulgação e alteração de leis como formas de permitir uma sociedade mais coesa.

Em verdade, o estudo da economia tem como objeto as escolhas dos homens em um cenário de bens escassos, uma análise econômica necessariamente descreve uma situação segundo as constantes e algumas variáveis previsíveis ${ }^{44}$. O Direito, por sua vez, tem como função o controle social sob a teleologia de uma sociedade justa. Nesse sentido, o estudo da economia aplicado as normas é uma importante ferramenta para criar um ordenamento legal mais eficiente e capaz de maximizar o proveito dos direitos ${ }^{45}$.

Sob esses fundamentos, os regimes de proteção à atividade intelectual foram um dos objetos mais estudados pela supramencionada escola recebendo uma análise crítica que fomentou o novo sistema de proteção legal justificados por premissas econômicas ${ }^{46}$. Consequentemente, a adoção do mecanismo de proteção equivalente a propriedade tem como justificativa a implantação de um remédio a uma falha assimétrica de mercado 47 .

Uma análise econômica do Direito de Propriedade Intelectual tem como início a constatação de que ideias, informações, são bens de natureza pública ${ }^{48}$ no sentido de que seu uso por A não excluí B de usar, ambos podem usufruir da mesma informação ao mesmo tempo. Todavia, apesar de não ser um bem consumível a circulação demasiada de informações gera a desvalorização dessa ${ }^{49} \mathrm{em}$ decorrência do valor marginal ${ }^{50}$.

Nesse diapasão, devido a essa natureza econômica há configurado a potencialidade de um cenário, assumindo a premissa de que a expressão a partir do momento que for comercializada será de conhecimento de potencialmente todos, onde o criador e o copiador competirão no mercado

\footnotetext{
Law and economics. $6^{\text {th }}$ ed. Berkeley: Berkeley Law Books, 2016, p. 3. Disponível em: $<$ scholarship.law.berkeley.edu/books/2. Acesso em: 12 out 2018.

${ }^{44}$ MISES, Ludwig Von. Ação humana: um tratado de economia. 3.1 ed. São Paulo: Instituto Ludwig von Mises Brasil, 2010, p. 417-418.

45 JOLLS, Christine; SUNSTEIN, Cass R.; THALER, Richard. A behavioral approach to law and economics. Stanford Law Review, [s.1.], pp. 1471-1550, may. 1998, p. 1476.

46 "The rise of property rhetoric in intellectual property cases is closely identified not with common law property rules in general, but with a particular economic view of property rights. This view, which emerges from a branch of law and economics movement, emphasizes the importance of private ownership as the solution to the economic problem known as the 'tragedy of the commons.' The central idea here is that joint or public ownership of a piece of property is inefficient, because non-owners who use the property have no incentive to take care of it and will therefore overuse it". LEMLEY, Mark A. Property, Intellectual Property, and Free Riding. Texas Law Review, [s.1.], vol. 83, issue 291, 2004, p.8.

${ }^{47}$ GORDON, Wendey J. Asemetric market failure and prisioner's dilemma in intellectual property. University of Dayton Law Review, [s.1.], vol. 17, nº 3, pp. 853-869, may. 1992, p.854.

${ }^{48}$ LEMLEY, Mark A. Ex Ante versus Ex Post Justifications for Intellectual Property. The University of Chicago Law Review, [s.1.], vol 71, issue 129, pp 129-149, 2004, p. 129.

49 POSNER, Richard. Intellectual Property: The Law and Economics Approach. Journal of Economic Perspectives, [s.1.], vol 19, n 2, pp-57-73, spring 2005, p. 66.

${ }^{50} \mathrm{O}$ valor marginal de acordo com a tradição neoclássica tem como premissas de que quanto mais abundante é um bem menor é o seu valor. A lei da demanda e da oferta.
} 
explorando o mesmo bem. Todavia, o autor ou inventor de uma expressão ou técnica dedicaram um investimento de dinheiro e tempo na elaboração de sua atividade criativa a contraposto do copiador que somente terá o custo material de copiar sendo essa hipótese uma falha de mercado ${ }^{51}$.

Consequentemente, a ausência de um auxílio legal é um desincentivo às mentes criativas a empreenderem na área da inovação ou desenvolverem atividades de criação de trabalhos artísticos ou científicos.

No caso do Direito das Marcas, o argumento em favor do Direito Intelectual é mais ligado a uma noção de evitar a confusão dos consumidores e, também, de concorrência desleal ${ }^{52}$. A divergir dos direitos autorais e de patentes, as marcas e indicações geográficas tem como função a identificação do produto, serviço e da empresa.

Em suma, o cerne do argumento apresentado em favor a propriedade intelectual é o de controlar o fluxo de informações sobre ideias ${ }^{53}$ como um incentivo aos criadores, gerando uma escassez artificial sobre um bem não escasso com o fim de impedir a redução do valor marginal em desfavor ao titular do direito ${ }^{54}$. Entretanto, o supramencionado instituto, na prática, não cria obstáculos a circulação das informações, mas sim ao uso das informações proibindo copiadores de replicarem a expressão ou recriarem a técnica ${ }^{55}$. Portanto, as leis de patentes e de direitos autorais incentivam os autores e inventores a divulgar técnicas e expressões.

Ademais, o mecanismo de proteção a propriedade intelectual, sob o argumento da teoria do assimetric market failure, exige mais 1 (uma) condição, para garantir um cenário propício para exploração da atividade intelectual, que é a possibilidade da emersão de um mercado da expressão no qual o titular do direito de propriedade intelectual possa barganhar com consumidor e outros

\footnotetext{
${ }^{51}$ GORDON, Wendey J. Asemetric market failure and prisioner's dilemma in intellectual property. University of Dayton Law Review, [s.1.], vol. 17, $\mathrm{n}^{\circ}$ 3, pp. 853-869, may. 1992, p.854.

52 POSNER, Richard. Intellectual Property: The Law and Economics Approach. Journal of Economic Perspectives, [s.1.], vol 19, n 2, pp-57-73, spring 2005, p. 62.

53 "On this explanation, intellectual property rights exist not to encourage the creation and dissemination of an idea, but to suppress efficiently the overuse of the idea". LEMLEY, Mark A. Ex Ante versus Ex Post Justifications for Intellectual Property. The University of Chicago Law Review, [s.l.], vol 71, issue 129, pp 129-149, 2004, p. 142.

54 "[w]ithout the artificial scarcity created by the protection of one's likeness, that likeness would be exploited commercially until the marginal value of its use is zero. ... [I]t would be overused, as each user will not consider the externality effect his use will have on others". Matthews v Wozencraft, 15 F3d 432,437-38 \& n 2 (Fed Cir 1994).

${ }^{55}$ GORDON, Wendey J. Asemetric market failure and prisioner's dilemma in intellectual property. University of Dayton Law Review, [s.1.], vol. 17, $\mathrm{n}^{\circ}$ 3, pp. 853-869, may. 1992, p.855.
} 
produtores $^{56}$, preferencialmente de forma consensual ${ }^{57}$. Dessa forma, o objetivo final é o equilíbrio entre os players $^{58}$ permitido ajustar a falha de mercado para que os titulares dos direitos de propriedade intelectual possam celebrar contratos.

\subsection{A teoria dos jogos e a propriedade intelectual}

Consoante o fundamentado, o principal objetivo do instituto de propriedade intelectual é a existência de incentivos e garantias legais para assegurar que os criadores - autores e inventores possam dispor desses direitos por meio de licenças formando assim um mercado para atividade criativa. Nessa toada, uma análise "fria” e estática não é o suficiente para justificar o mecanismo atual do Direito de Propriedade Intelectual, sendo necessário o teste através de uma análise mais sofisticada.

A teoria dos jogos a divergir das principais teorias no meio acadêmico tem como fundamento teórico o equilíbrio parcial, formulando análises mais dinâmicas e, portanto, mais realísticas e pedagógicas, vis-à-vis, as demais teorias têm como alicerce a noção de equilíbrio geral ${ }^{59}$. Consequentemente, o foco dessa escola econômica é o estudo das decisões dos agentes racionais em situações hipotéticas para elaboração de modelos que simplifiquem a realidade ao ponto de torna-la mais fácil de analisar e entender ${ }^{60}$, id est, a confecção de estratégias em escala microeconômica.

Sob esses fundamentos, a teoria dos jogos resume situações reais em diferentes modelos com o fim de descobrir qual melhor estratégia para os jogadores. Exempli gratia, no cenário da propriedade intelectual, a teoria dos jogos teria como função desvendar qual é a melhor estratégia, a dominante, para cada jogador, averiguando se esse instituto é eficiente ou não.

56 "Thus the first condition of asymmetric market failure addresses whether an intellectual property system is
needed in the first place. The second condition for asymmetric market failure address whether the intellectual
property system will be practicable, and really provide the incentives desired. (..) If markets do not evolve for a
particular creative work or use - say for example that bargaining is impeded by problems such as externalities,
high transaction costs, or the impossibility of identifying the copyright proprietor - and no market substitutes
(e.g. Coasian firms, compulsory licenses) are available, then if the copyright law prohibited copying in that area
it would simply be preventing copying without yielding creators any monetary advantage. That would be
undesirable".GORDON, Wendey J. Asemetric market failure and prisioner's dilemma in intellectual property.
University of Dayton Law Review, [s.l.], vol. 17, $\mathrm{n}^{\circ} 3$, pp. 853-869, may. 1992, p. 857.
57 A habilidade do titular do direito de propriedade intelectual em formular um mercado para sua propriedade é
a principal função do mecanismo de defesa e também o resultado preferível, uma vez que a suplantação de um
instituto de licença compulsória possui custos de transações superiores aos da licença voluntária. GORDON,
Wendey J. Asemetric market failure and prisioner's dilemma in intellectual property. University of Dayton Law
Review, [s.1.], vol. 17, no 3, pp. 853-869, may. 1992, p. 858.
58 BARBOSA, Denis Borges. Uma introdução a propriedade intelectual. 2 ed. [s.1]:Editora Lumen Juris, 2010,
p.75.
59 FOSS, Nicolai. Austrian economics and Game Theory: a stocktaking and an evaluation. The Review of ${ }^{59}$ FOSS, Nicolai. Austrian economics and Game Theory: a stocktakin
Austrian Economics, [s.1.], v. 13, issue 1, pp-41-58, feb. 2000, p. 47.

${ }^{60}$ OSBORNE, Martin J. An introduction to Game Theory. Toronto: Oxford University Press, 2000, p. 2. 
Sob esses fundamentos, no Direito, o principal modelo para a análise econômica é o dilema dos prisioneiros, usado para negociação de $\operatorname{contratos}^{61}$, relações processuais ${ }^{62}$ e, até mesmo, no Direito Penal, mais presente e notório no instituto da colaboração premiada ${ }^{63}$.

O mencionado jogo cria a hipótese de que há 2 (dois) prisioneiros - A e B - que cometeram 1 (um) crime e estão detidos. A autoridade policial possui evidências suficientes para colocar ambos na prisão por 1 (um) ano, porém o designo dela é colocar os investigados no máximo de tempo possível. Nesse sentido, a autoridade oferece aos 2 (dois) suspeitos, que estão em regime de incomunicabilidade e não possuem certeza da possível escolha do outro, a mesma oportunidade de delatar o "sócio", que pagará 5 (cinco) anos, em troca da própria liberdade. Todavia, caso os 2 (dois) delatem irão pegar 2 (dois) anos de pena. Ambos os prisioneiros têm conhecimento inequívoco de que a mesma oferta foi oferecida ao outro e são indivíduos racionais que priorizam a si mesmo.

O cenário mencionado possui os seguintes resultados: a) A delata e B permanece calado, o primeiro sai em liberdade e B será sentenciado a 5 (cinco) anos de penalidade; b) B delata e A permanece calado, sendo B quem sai em liberdade e A quem responderá 5 (cinco) anos; c) Os 2 (dois) delatam e responderão 2 (dois) anos; e, por fim, d) Ambos permanecem calados e respondem há apenas 1 (um) ano. Nessa conjectura, 2 (dois) resultados são bons apenas para 1 (um) e, por essa razão, é o principal incentivo para a colaboração premiada e apenas em 1 (um) cenário é excelente para os 2 (dois).

Na conjectura apresentada, é fácil deduzir que a escolha lógica para os 2 (dois) é o silêncio. Entretanto, a dificuldade do dilema reside no desconhecimento da ação do "parceiro" e no alto custo da confiança, é exatamente nisso em que se formula a estratégia do jogo da autoridade policial que quer que ambos cooperem. Nessa hipótese a estratégia dominante para cada player é delatar sendo essa a teoria do equilíbrio de $\mathrm{Nash}^{64}$.

O dilema dos prisioneiros pode ser aplicado ao Direito de Propriedade Intelectual da seguinte forma: A e B agora são empresários, racionais, rivais, que disputam o mercado de motor, em equilíbrio. Ambos desejam auferir maior lucro e sabem que a única forma é através de uma nova tecnologia ou copiando uma nova tecnologia. Todavia não há nenhuma lei de proteção à propriedade

\footnotetext{
${ }^{61}$ CZELUSNIAK, Vivian Amaro; RIBEIRO, Marcia Carla Pereira. Cooperação para Efetividade dos Contratos de Transferência de Tecnologia: uma análise juseconômica. Economic Analysis of Law Review, Brasília, v. 4, $\mathrm{n}^{\mathrm{o}} 1$,p. 21-34, Jan./jun. 2013, p. 27.

${ }^{62}$ SILVA, Luciana Aboim Machado Gonçalves da; VITALE, Carla Maria Franco Lameira. Aplicação da teoria dos jogos na mediação de conflitos: o equilíbrio de nash como estratégia de maximização de ganhos. Revista de Formas Consensuais de Solução de Conflitos, [s.1.], v.2, n.1, pp. 124-139, ,2016, p. 129.

${ }^{63}$ GOMES, Luiz Flávio; SILVA, Marcelo Rodrigues da. Criminalidade organizada e justiça penal negociada: delação premiada. Revista de Filosofia do Direito, do Estado e da Sociedade, Natal, v. 6, n. 1, pp. 164-175, jan./jun., 2015, p.172.

${ }^{64}$ COOTER, Robert; ULEN, Thomas. Law and economics. 6th ed. Berkeley: Berkeley Law Books, 2016 , p. 35. Disponível em: <scholarship.law.berkeley.edu/books/2. Acesso em: 12 out 2018.
} 
intelectual. Desse cenário podem ser supostas as seguintes alternativas: a) ambas as partes decidem inovar e lucram 100 (cem) mil reais; b) apenas 1 (uma) das partes decide inovar e a outra copiar, fazendo com que a primeira tenha prejuízo de 50 (cinquenta) mil e outra um lucro de 150 (cento e cinquenta) mil reais; c) as 2 (duas) partes decidem copiar levando 0 (zero) de lucro, mantendo o estado de equilíbrio original ${ }^{65}$. Assim como no outro exemplo, A e B não possuem conhecimento quanto a qual é escolha do seu rival, logo a estratégia dominante, nesse exemplo, é a "c" em virtude do pouco risco de prejuízo.

A mudança desse cenário ocorre somente quando há custo para copiar a nova tecnologia, nesse cenário os 2 (dois) players possuirão incentivos para não-copiar, configurando os resultados em: a) ambas as partes decidem inovar e lucram 100 (cem) mil reais; b) apenas 1 (uma) das partes decide inovar e a outra copiar, todavia, em virtude da lei, o copiador sofre 150 (cento e cinquenta) mil reais de prejuízo e o criador 100 (cem) mil reais de lucro, gastando 50 (cinquenta) mil com o custo legal para reaver os lucros do copiador; c) as 2 (duas) partes decidem copiar levando 0 (zero) de lucro. Nessa descrição a estratégia dominante passa a ser a "a" em decorrência da potencialidade do lucro e ao menos manter a paridade na concorrência.

Nas 2 (duas) hipóteses apresentadas, há 1 (um) terceiro jogador, o Estado, que possui 2 (dois) padrões de comportamentos: a) impedir a cópia e b) não impedir ${ }^{66}$. Nesse modelo de jogo, é pressuposto que o terceiro jogador atuará com condutas extremas que podem ou não aplicar com total eficácia uma política de proteção de propriedade intelectual ${ }^{67}$.

Entretanto, uma analise mais realista deve levar em conta outros padrões de comportamento do Estado e dos outros 2 (dois) jogadores que é a elaboração de um cenário de imperfeição na aplicação da lei de propriedade intelectual e os incentivos positivos e negativos para as partes investirem em inovação.

\subsection{O contrato de propriedade intelectual no dilema dos prisioneiros}

Consoante o exposto, o contrato é o principal método autocompositivo disponível, caracterizado pela convergência do interesse das partes em solucionar um problema em comum ou

\footnotetext{
${ }^{65}$ GORDON, Wendey J. Asemetric market failure and prisioner's dilemma in intellectual property. University of Dayton Law Review, [s.1.], vol. 17, no 3, pp. 853-869, may. 1992, p. 863-865.

${ }^{66}$ SOUZA, Ananda Portes; TEXEIRA, Andre Costa Ferreira de Belfort. A teoria dos jogos e o direito: entendendo a aplicabilidade da teoria dos jogos ao direito a partir dos jogos de gun jumping e de investimento em propriedade intelectual. Revista de Direito, Inovação, Propriedade Intelectual e Concorrência, Minas Gerais, v. 1, n.2, pp. 21-41, jul/dez.2015, p. 30.

${ }^{67}$ CARRARO, André. Propriedade Intelectual e Teoria dos Jogos. $1^{a}$ ed. Santa Cruz do Sul: EDUNISC, 2005, p. 50. 
relacionado. Nesse sentido, em um cenário onde a aplicação da lei é imperfeita há incentivos para que as partes ao invés de litigarem resolvam entre si, com uma celebração de um contrato, a controvérsia sendo a exceção o apelo ao método heterocompositivo.

Isto é, no cenário apresentado no último tópico, A, B e o Estado, cada 1 (um) possue apenas 2 (duas) ações copiar ou inovar, no caso dos empresários, e impedir a cópia ou não impedir a cópia. Todavia, em um cenário de aplicação da lei imperfeita há os seguintes possíveis resultados em relação a aplicação da lei: a) a decisão é aquém ao esperado gerando custos legais superiores a decisão, logo prejuízo ao inovador; b) a decisão é superior gerando prejuízo ao copiador e lucro para o inovador; c) a decisão é balanceada e não gera perdedores e ganhadores, mantendo o equilíbrio entre as 2 (duas) empresas; d) a decisão é condenatória e gera prejuízo ao copiador, mas não causa lucro ao inovador; e e) copiador e inovador entram em um acordo em que ambos lucram, o criador por levar uma porcentagem do valor da atividade comercial do copiador e o copiador retém uma parte do dinheiro das vendas.

Essas 5 (cinco) possibilidades de resultados na aplicação da lei abrem 2 (duas) ações a A e B, negociar ou litigar. Nesse cenário, considerando que ambos possuem o interesse de maximizar seus lucros e evitar prejuízos imediatos, além da incerteza de qual será a decisão, o melhor cenário é "e" em que ambas as partes lucram e evitam o prejuízo imediato ${ }^{68}$. Em virtude de somente no cenário "e" o copiador possui alguma perspectiva de lucro, essa será a única hipótese em que haverá de fato ganhos, o que permite ao inovador a vantagem necessária para uma barganha ${ }^{69}$.

Nesse diapasão, em uma situação em que o mecanismo de aplicação da lei é imperfeito, seja pela imprevisibilidade do conteúdo da decisão ou pela morosidade da decisão, a estratégia dominante para os 2 (dois) players racionais que esperam a maximização do lucro é cooperar entre si e achar o meio termo de ambas as pretensões ${ }^{70}$.

Sob essa perspectiva, considerando o objetivo do Direito Intelectual é a supressão da falha do mercado através da disposição de instrumentos legais para criar/estimular o mercado, a função da lei

\footnotetext{
68 "Trials are very expensive everywhere. The notorious cost of litigation has generated countless lawyer jokes that circulate on the internet (...) Given these costs, being drawn into a legal suit is a punishment in itself for the parties, but not their lawyers". COOTER, Robert; ULEN, Thomas. Law and economics. 6th ed. Berkeley: Berkeley Law Books, 2016, p.403-404. COOTER, Robert; ULEN, Thomas. Law and economics. 6th ed. Berkeley: Berkeley Law Books, 2016, p. 74. Disponível em: <scholarship.law.berkeley.edu/books/2. Acesso em: 12 out 2018.

${ }^{69}$ MELLO, Maria Tereza Leopardi. Propriedade Intelectual e Concorrência. Revista Brasileira de Inovação, Rio de Janeiro, v. 8, nº 2, p. 371-402, julho/dezembro 2009, p. 395-396.

70 "To develop an economic theory of property, we must first develop the economic theory of bargaining games. At first you may not see the relevance of this theory to property law, but later you will recognize that it is the very foundation of the economic theory of property" (grifos acrescidos). COOTER, Robert; ULEN, Thomas. Law and economics. 6th ed. Berkeley: Berkeley Law Books, 2016, p. 74 . Disponível em: $<$ scholarship.law.berkeley.edu/books/2. Acesso em: 12 out 2018.
} 
de propriedade intelectual deve ser a criação de incentivos para o copiador e inovador cooperarem ${ }^{71}$. Dessa forma, a prioridade da mencionada legislação deve ser não oferecer obstáculos a celebração de contratos e facilitar a negociação entre copiador e criador.

Portanto, em decorrência da imperfeição na aplicação da lei, ou até mesmo do seu texto, e a natureza de difícil controle do uso do bem imaterial, que é o objeto da propriedade intelectual, o Direito de Propriedade Intelectual, sob uma justificativa econômica, deve sempre prezar pela criação de incentivos para que as partes possam barganhar. De fato, o principal efeito da existência desse instituto é a promoção, por meios artificiais, de um mercado em que a assimetria entre copiar e criar é corrigida por uma vantagem legal para contratar, principalmente um contrato com o intuito de evitar um processo judicial, id est, é criar o equilíbrio de mercado entre os titulares de direito de propriedade intelectual e copiadores. Nessa toada, a análise econômica da propriedade intelectual deve importar a metodologia da microeconomia para os estudos da sua eficácia legal, levando em consideração a subjetividade dos agentes na elaboração das suas cláusulas legais.

\section{O DIREITO À PROPRIEDADE INTELECTUAL, O CONTRATO E OS JOGOS SOB UMA VISÃO AUSTRÍACA}

As análises econômicas descritas foram confeccionadas segundo a tradição neoclássica, estudando o processo de mercado em equilíbrio, propondo incentivos positivos e negativos para que as leis de propriedade intelectual fossem capazes de "curar" a falha de mercado e a disparidade entre criadores e copiadores.

A apresentação dos modelos da teoria dos jogos marcou uma transição no método analítico para um cenário de quase-dinâmica, ou equilíbrio parcial, no estudo da macroeconomia. Em outras palavras, o ponto de partida das hipóteses são os elementos subjetivos, relativos aos agentes, a diversidade de opções de ações e estratégias, e os resultados consequentes para alcançar um cenário

\footnotetext{
${ }^{71}$ A cooperação entre o titular dos direitos de propriedade intelectual é sempre preferrível em virtude do baixo custo de transação, mesmo a hipótese de uma licenciação compulsória concedida pelo o Estado-Juiz não é um mecanismo tão eficaz quanto o método autocompositivo, sobre isto: "The ability of users to form markets under copyright is also important for another reason: administrative costs. Let us say that after having supposedly cued the first market failure - the author's difficulty in excluding nonpayers - by setting up a system of intellectual property rights, Congress decides to cure any secondary market failures that arise that could block licensing of copyrighted works. Perhaps Transaction costs block licensing in a particular entertainment industry, and the legislators cue the market failure by setting up a scheme like compulsory licensing, or by explicitly authorizing courts to give continuing damage remedies (...) but these schmes are likely to be much more expensive and cumbersome than ordinary markets are. Further, since their administrative cost are high, there will be gaps in coverage".GORDON, Wendey J. Asemetric market failure and prisioner's dilemma in intellectual property. University of Dayton Law Review, [s.1.], vol. 17, nº 3, pp. 853-869, may. 1992, p. 858.
} 
no qual os participantes estejam em equilíbrio. Isto é, tenham como a única opção de maximização dos seus lucros e minimização de suas perdas em uma estratégia benéfica a ambos concorrentes.

Nesse diapasão, convêm desenvolver uma analise ainda mais sofisticada do fenômeno econômico com os ensinamentos da tradição da Escola Austríaca de Economia ${ }^{72}$. Ademais, é importante ressalvar a diferença entre o fenômeno econômico e a ciência econômica, a qual está limitada a previsões de probabilidade qualitativa em virtude da incapacidade humana de assimilar todos os elementos necessários para uma previsão quantitativa ${ }^{73}$. Essa é a premissa básica da qual os economistas da tradição austríaca elaboram suas análises, com o fim mais pedagógico do que de previsão.

Consequentemente, o estudo do fenômeno econômico é feito através de alguns axiomas sob os quais são construídos os fundamentos de qualquer argumento sobre economia, são eles: a) a ação humana, b) o tempo e, por fim, c) o conhecimento ${ }^{74}$.

A ação humana é definida como a conduta propositada ${ }^{75} \mathrm{com}$ o intuito de sair do estado inicial de insatisfação para o de maior satisfação ${ }^{76}$, sendo sua natureza inerente a escolha entre negociar os recursos do presente para alcançar o objetivo no futuro ${ }^{77}$. O axioma da ação humana pressupõe a escassez de recursos, o custo das condutas e a necessidade de buscas meios e fins eficientes. Em seguida, há o axioma do tempo, sob uma definição de tempo real ou newtoniano ${ }^{78}$, que é a relação entre causa e efeitos provocado pela ação humana, sendo o elo entre o passado e o futuro, e tendo o agente a capacidade de distinguir antes, durante e depois, da sua ação ${ }^{79}$, é um elemento escasso, uma vez que sempre é negociado o presente em favor de um futuro incerto ${ }^{80}$. Por fím, há o último elemento estruturante da ação humana, o conhecimento sobre os meios e os fins que guiam a conduta, o homem

\footnotetext{
${ }^{72}$ A Escola Austríaca tem como seu fundador Carl Menger que em 1871 lançou sua obra Princípios da Economia Política que liderou o debate da teoria marginalista do valor. As raízes do pensamento dessa tradição remota a São Tomás de Aquino, sucedido pelos escolásticos tardios, David Hume e, por fim, Adam Smith. Com o foco da economia como um fenômeno humanístico, homo agens, divergindo do pensamento de outras escolas do Século X que enxergam o homem como homo aeconomicus. IORIO, Ubiratan Jorge. Ação, tempo e conhecimento: A Escola Austríaca de economia. São Paulo: Instituto Ludwig von Mises, 2011, p. 15-16.

${ }^{73}$ MISES, Ludwig Von. Ação humana: um tratado de economia. 3.1 ed. São Paulo: Instituto Ludwig von Mises Brasil, 2010, p. 152.

${ }^{74}$ IORIO, Ubiratan Jorge. Ação, tempo e conhecimento: A Escola Austríaca de economia. São Paulo: Instituto Ludwig von Mises, 2011, p. 30.

${ }^{75}$ MISES, Ludwig Von. Ação humana: um tratado de economia. 3.1 ed. São Paulo: Instituto Ludwig von Mises Brasil, 2010, p. 35.

${ }^{76}$ MISES, Ludwig Von. Ação humana: um tratado de economia. 3.1 ed. São Paulo: Instituto Ludwig von Mises Brasil, 2010, p. 37-38.

${ }^{77}$ MISES, Ludwig Von. Ação humana: um tratado de economia. 3.1 ed. São Paulo: Instituto Ludwig von Mises Brasil, 2010, p. 125-131.

${ }^{78}$ IORIO, Ubiratan Jorge. Ação, tempo e conhecimento: A Escola Austríaca de economia. São Paulo: Instituto Ludwig von Mises, 2011, p. 18.

${ }^{79}$ MISES, Ludwig Von. Ação humana: um tratado de economia. 3.1 ed. São Paulo: Instituto Ludwig von Mises Brasil, 2010, p. 134.

${ }^{80}$ MISES, Ludwig Von. Ação humana: um tratado de economia. 3.1 ed. São Paulo: Instituto Ludwig von Mises Brasil, 2010, p. 135-136.
} 
só age se tiver uma previsão que os meios empregados para os fins são eficientes para alcançar os efeitos que ele julga que irão ocorrer. Em razão do elemento volitivo, o conhecimento é sempre imperfeito, do contrário o homem seria um autômato que apenas reagiria a incentivos ${ }^{81}$, $\log$ a ação é limitada por elementos que o agente conhece e por outros desconhecidos, sendo uma probabilidade de caso $^{82}$.

Consequentemente, o homo agens, teorizado pelos economistas austríacos, é inerentemente um empreendedor divergindo do homo aeconomicus, na medida em que a eficiência e o agir é condicionado ao conhecimento do agente dos meios e fins ${ }^{83}$ apresentando um comportamento volitivo que o diferencia de um autômato "maximizador de eficiência". Id est, o homo aeconomicus apenas reage aos incentivos externos, portanto, não há o elemento da vontade em sua atividade.

A tríade apresentada é fundamental para a aplicação correta da lei da utilidade marginal, sendo todo julgamento de valor algo que está extrínseco ao objeto e intrínseco ao agente ${ }^{84}$. Nessa toada, os preços adequados são formulados pelas ações coordenadas através do processo de mercado, no qual por meio de erros e acertos são descobertos pelos players $^{85}$.

Em suma, a análise econômica da Escola Austríaca tem como o pressuposto o agente de conhecimento imperfeito, que age de maneira subjetiva e possui uma preferência temporal específica para cada ação. Por essa razão, é denominada uma análise dinâmica entendendo o mercado como um processo $^{86}$ no qual os atuantes estão sempre, através da sua criatividade, inovando, errando, acertando, aprendendo e corrigindo as falhas de mercado. Ademais, assim como a Teoria dos Jogos, é aplicação de métodos inerentes a microeconomia na macroeconomia.

\footnotetext{
${ }^{81}$ MISES, Ludwig Von. Ação humana: um tratado de economia. 3.1 ed. São Paulo: Instituto Ludwig von Mises Brasil, 2010, p. 139.

${ }^{82}$ MISES, Ludwig Von. Ação humana: um tratado de economia. 3.1 ed. São Paulo: Instituto Ludwig von Mises Brasil, 2010, p. 144.

${ }^{83}$ KIRZNER, Israel M. Competição e atividade empresarial. São Paulo: Instituto Ludwig von Mises, 2012 , p. 40.

${ }^{84}$ ROTHBARD, Murray N. Man, Economy, and State: a treatise on economic principles with Power and Market government and the economy. 2. ed. Auburn: Ludwig von Mises Institute, 2009, p. 27-28.

${ }^{85}$ KIRZNER, Israel M. Competição e atividade empresarial. São Paulo: Instituto Ludwig von Mises, 2012 , p. 22.

86 “O mercado não é um local, uma coisa, uma entidade coletiva. O mercado é um processo, impulsionado pela interação das ações dos vários indivíduos que cooperam sob o regime da divisão do trabalho. As forças que determinam a - sempre variável — situação do mercado são os julgamentos de valor dos indivíduos e suas ações baseadas nesses julgamentos de valor. A situação do mercado num determinado momento é a estrutura de preços; isto é, o conjunto de relações de troca estabelecido pela interação daqueles que estão desejosos de vender com aqueles que estão desejosos de comprar. Não há nada, em relação ao mercado, que não seja humano, que seja místico. O processo de mercado resulta exclusivamente das ações humanas. Todo fenômeno de mercado pode ser rastreado até as escolhas específicas feitas pelos membros da sociedade de mercado". MISES, Ludwig Von. Ação humana: um tratado de economia. 3.1 ed. São Paulo: Instituto Ludwig von Mises Brasil, 2010, p. 315-316.
} 


\subsection{A teoria do equilíbrio, o processo contínuo de mercado e a propriedade intelectual}

Consoante a apresentação dos fundamentos principais da tradição austríaca é perceptível o maior grau de complexidade que uma análise econômica exige. Atualmente, o maior "ponto de estresse" e que tem sido o objeto do trabalho de alguns economistas austríacos é a visão do mercado como um estado em equilíbrio, em decorrência da teoria do equilíbrio geral, em face da noção do mercado como processo em que os agentes através de suas ações coordenam suas preferencias e influenciam uns aos outros rumo a descoberta dos preços adequados para os produtos naquele momento $^{87}$.

O ponto de partida das correntes majoritárias é a pressuposição de que os gostos e preferencias dos agentes já estão definidos sendo apenas relevante a avaliação da competição entre quantidade e qualidade de produtos e serviços, sendo esses os elementos essenciais para a teoria do preço ${ }^{88}$. Consequentemente, há uma predominância da linguagem matemática e a intenção de prever preços e comportamentos de acordo com as equações estatísticas ${ }^{89}$. Em contraposição a essa visão, o foco dos economistas austríacos é a mudança dos preços, empregando suas analises no estudo das preferenciais dos agentes no mercado e como essas influenciam na formação dos preços ${ }^{90}$. Por essa razão, há a predominância da avaliação através de uma linguagem argumentativa.

Consequentemente, há a ênfase do estado de alerta empresarial ${ }^{91}$ que é essencial para as mudanças de preços. É através da criatividade, proatividade e o estado de alerta de alguns players do mercado, que ao compreender um fenômeno de mudança nas preferencias dos consumidores ou uma falha técnica que gere desperdício de recursos, que a mudança do preço ocorre ${ }^{92}$. Ademais, o referido estado dura o tempo da dispersão do conhecimento aos demais players, nessa situação hipotética

\footnotetext{
${ }^{87}$ Os economistas da tradição austríaca Kirzner e Boettke, sendo o primeiro um dos mais influentes, continuam a desenvolver suas críticas com base na teoria geral do equilíbrio e continuam negligenciam os avanços da teoria dos jogos. FOSS, Nicolai. Austrian economics and Game Theory: a stocktaking and an evaluation. The Review of Austrian Economics, [s.1.], v. 13, issue 1, pp-41-58, feb. 2000, p. 42.

${ }^{88}$ Essa noção decorre da simplificação do homo aeconomicus que atua unicamente como um "maximizador" de utilidade, pressupondo conhecimento perfeito e preferenciais quase homogêneas, sendo, por essa razão, uma hipótese de um autômato que apenas reage aos estímulos externos.

${ }^{89}$ KIRZNER, Israel M. Competição e atividade empresarial. São Paulo: Instituto Ludwig von Mises, 2012, p.15-16.

${ }^{90}$ KIRZNER, Israel M. Competição e atividade empresarial. São Paulo: Instituto Ludwig von Mises, 2012 , p.16-17.

91 O mencionado conceito é definido pelo estado de alerta as mudanças de preferenciais e as necessidades de uma mudança de alocação de recursos em uma nova maneira. KIRZNER, Israel M. Competição e atividade empresarial. São Paulo: Instituto Ludwig von Mises, 2012, p. 45.

${ }^{92}$ KIRZNER, Israel M. Competição e atividade empresarial. São Paulo: Instituto Ludwig von Mises, 2012 , p. 70 .

PIDCC, Aracaju/Se, Ano VIII, Volume 13 no 02, p.146 a 174 Jul/2019 | www.pidcc.com.br
} 
ocorre o equilíbrio do mercado e torna a atividade empresarial ${ }^{93}$ uma relação de maximização de utilidade ${ }^{94}$.

No contexto da propriedade intelectual - mais especificamente a respeito da lei de patentes, modelo de utilidade ou até mesmo desenho industrial ${ }^{95}$-, o inovador assume uma função empresarial $^{96}$ em elaborar uma nova técnica ou processo de produção capaz de desequilibrar o mercado e criar um novo equilíbrio ${ }^{97}$. Esse empresário possui o conhecimento advindo de um investimento (seja de tempo, dinheiro e etc.) que será dirigido a uma expectativa de lucro. Em um processo de mercado é natural que a medida em que o agente empregue esse conhecimento os demais concorrentes trabalhem para copiar a função conseguida pelo ato criativo.

Nessa toada, o Direito Intelectual tem como função, o impedimento da conduta injusta dos agentes - a interceptação do segredo por atividades ilegais ou de má-fé. Ademais, em virtude de um viés desenvolvimentista é empregado a concessão de patentes e modelos de utilidade sob a condição de publicar o conhecimento em troca de uma maior vantagem para barganhar. Em outras palavras, consoante essa perspectiva, o instituto da propriedade intelectual, desde que não tenha custos administrativos nulos e aplicação perfeita no contencioso ${ }^{98}$, em regra não cria monopólios ou restrições de mercados. Contraditoriamente, a premissa de uso exclusivo e a intenção em controlar o

\footnotetext{
${ }^{93} \mathrm{O}$ conceito de empresa usado é uma combinação do "empresário puro", aquele agente que está alerta as mudanças, e o "empresário proprietário" que age como o homo aeconomicous exemplificado. KIRZNER, Israel M. Competição e atividade empresarial. São Paulo: Instituto Ludwig von Mises, 2012, p. 34.

${ }^{94}$ KIRZNER, Israel M. Competição e atividade empresarial. São Paulo: Instituto Ludwig von Mises, 2012, p. 70-71.

${ }^{95}$ Apesar do desenho industrial ter como características uma maior ligação ao Direito das Marcas do que as patentes e modelos de utilidade, a apresentação de um produto pode influenciar as compras em razão do maior conforto que o designer do produto possa oferecer, por exemplo.

96 "Se não houver direito autoral nem registro de patentes, os inventores e autores estarão na posição de um empresário. Têm uma vantagem temporária em relação a outras pessoas. Como podem começar a utilizar mais cedo sua invenção, ou seu manuscrito, ou colocá-lo à disposição de outras pessoas (fabricantes, editores), têm a possibilidade de auferir lucros enquanto sua obra não é de domínio público. Tão logo a invenção ou o texto do livro venham a ser conhecidos pelo público, tornam-se "bens livres", e ao inventor ou ao autor resta apenas a glória". MISES, Ludwig Von. Ação humana: um tratado de economia. 3.1 ed. São Paulo: Instituto Ludwig von Mises Brasil, 2010, p. 753.

${ }^{97}$ Paradoxalmente a figura de um inventor, tal qual a de um empresário puro, é uma força de desequilíbrio, tal qual o economista Schumpeter idealizou, no mercado que através de suas ações guia os demais concorrentes ao equilíbrio. KIRZNER, Israel M. Competição e atividade empresarial. São Paulo: Instituto Ludwig von Mises, 2012, p. 71

${ }^{98} \mathrm{O}$ mecanismo perfeito de proteção à propriedade intelectual criaria um cenário de equilíbrio no qual um agente teria o verdadeiro monopólio de uma determinada técnica ou processo, por tempo determinado pela legislação. Nesse sentido, deve haver também um equilíbrio que estimulem os agentes a negociarem e não a litigarem. Ademais, em virtude da imperfeição na aplicação desse instituto o processo de mercado tende ao equilíbrio das forças o que não ocorreria caso a estratégia dominante dos concorrentes fossem copiar, gerando o desequilíbrio, que segundo Kirzner é: "um estado de desequilíbrio de mercado é caracterizado por ignorância generalizada. Os participantes do mercado não estão conscientes de oportunidades reais para trocas lucrativas que estão à sua disposição no mercado. O resultado desse estado de ignorância é que inúmeras oportunidades são perdidas". KIRZNER, Israel M. Competição e atividade empresarial. São Paulo: Instituto Ludwig von Mises, 2012, p 68-69.
} 
conhecimento - mais enfático nas patentes e direitos autorais -, é um instituto que promove o avanço ao tornar mais rápido a divulgação de um conhecimento que, em segredo industrial e a depender da natureza deste, levaria décadas a ser desvendado.

Sob o prisma austríaco, o foco na proteção à atividade criativa deve ser mais enfático na estimulação em criar um mercado e incentivar condutas de boa-fé dos agentes durante esse processo, vis-à-vis, a conceder status de direitos reais e aplicar a análise econômica referente aos direitos reais tradicionais. Em outras apalavras, a mentalidade do empresário como proprietário de recurso, um agente que deseja a maximização da exploração, é incompatível com a mentalidade disruptiva de criadores que melhor coadunam com a noção do empresário puro kirzenriano.

Considerando que o Direito Intelectual protege o criador, logo o estado de mente inerente a esse arquétipo, é equívoca a aplicação da análise econômica da propriedade intelectual como um direito real tradicional. Portanto, a prioridade do instituto da propriedade intelectual deve ter como foco a facilitação das negociações ao invés da exploração monopolística da expressão criativa e a análise econômica empregada deve ter como objeto a atividade empresarial kirzneriana e o processo de descoberta de preço. Nesse sentido, o desequilíbrio natural gerado momentaneamente pela atividade criativa deve ser protegido e não obstruído pela estrutura legal.

\subsection{A análise da teoria dos jogos e a crítica austríaca}

A teoria dos jogos como mencionado diverge da teoria neoclássica e, em seu emprego, possui algumas ideias que coadunam com a tradição austríaca. Em verdade, o percursor da teoria nos tempos modernos John Nash cursou apenas um curso de economia ministrado por Horselitz - economista austríaco e aluno de Mises que junto a Hayek e Dingwall traduziu do alemão para o inglês o livro Princípios da Economia Política de Carl Menger ${ }^{99}$ - e, mais tarde, em uma entrevista confessou a influência e a peculiar natureza da tradição austríaca em sua obra ${ }^{100}$. Outrossim, Morgenstein, coautor junto com Neumann do livro fundamental para o desenvolvimento da teoria dos jogos moderna, foi um economista austríaco, também disciplino de Mises, e responsável pela estrutura da teoria econômica do livro An Economic Theory of Game and Behaviour ${ }^{101}$. Logo, é clara a influência

\footnotetext{
${ }^{99}$ KELLY, Yvan J. Mises, Morgenstern, Hoselitz, and Nash: the austrian connection to early game theory. The Quartly Journal of Austrian Economics, [s.1.], v. 12, n 3, pp 37-42, 2009, p. 38-39.

${ }^{100}$ KELLY, Yvan J. Mises, Morgenstern, Hoselitz, and Nash: the austrian connection to early game theory. The Quartly Journal of Austrian Economics, [s.1.], v. 12, n 3, pp 37-42, 2009, p.40.

${ }^{101}$ Morgenstern sucedeu Hayek como diretor do Institute for Business Cycle Research em Viena.KELLY, Yvan J. Mises, Morgenstern, Hoselitz, and Nash: the austrian connection to early game theory. The Quartly Journal of Austrian Economics, [s.1.], v. 12, n 3, pp 37-42, 2009, p. 38.
} 
austríaca nas bases teórica da teoria dos jogos modernos, na qual há a convergência no emprego da análise mais dinâmica do processo de mercado.

Entretanto, apesar das raízes austríacas, a teoria dos jogos moderna aplicada a economia é passível de algumas críticas e apontamentos. A prima facie, o uso do método ${ }^{102}$, a linguagem pela qual é feita a análise econômica, matemático é um dos pontos criticados pelos austríacos uma vez que o uso de equações matemáticas per si não são suficientes para uma boa explicação lógica do fenômeno econômico ${ }^{103}$, sendo mais frequente, inclusive, que teorias ruins sejam apresentadas pela aplicação matemática ${ }^{104}$. Nesse sentido, os economistas austríacos possuem predileção pelo método argumentativo para explanar o fenômeno econômico, por entenderem que o homem é complexo demais para simplificações em termos matemáticos.

Outros pontos de discordâncias entre a abordagem da teoria dos jogos e a economia austríaca está na presunção da racionalidade perfeita dos agentes, do conhecimento perfeito e informações. Para a teoria dos jogos, o homem é entendido como um ser plenamente racional capaz de entender contextos e o mundo, já para Escola Austríaca a racionalidade é entendida como a capacidade criativa em criar/desvendar ${ }^{105}$ novas situações ${ }^{106}$. Na prática, essa é a diferença entre o homo aeconimicus e o homo agens, já previamente explanada.

Ademais, como já explanado, um dos fundamentos principais da análise austríaca é a noção do conhecimento assimétrico em um mercado, em que os atores não possuem a mesma informação de seus concorrentes. Dessa maneira, as críticas austríacas se fundamentam nas noções neoclássicas imbuídas na teoria dos jogos.

Entretanto, não há uma incompatibilidade essencial entre a economia austríaca e a teoria dos jogos. O avanço dos jogos de coordenação, onde há diversos jogadores com conhecimento e desígnios diferentes, é o ponto de interseção em que ambas escolas podem beneficiar-se, a teoria dos jogos com

\footnotetext{
${ }^{102}$ Há 2 (duas) formas de proceder uma hipótese/ a argumentativa e a matemática, na termologia de Mises, respectivamente: cataláxia lógica e cataláxia matemática. MISES, Ludwig Von. Ação humana: um tratado de economia. 3.1 ed. São Paulo: Instituto Ludwig von Mises Brasil, 2010, p. 412.

${ }^{103}$ CACHANOSKY, Nicolás. Spontaneous orders and game theory: a comparative conceptual analysis. Revista de Instituciones, Ideas y Mercados, [s.1.], n 52, pp. 52-88, may. 2010, p. 60.

${ }^{104}$ Nas palavras de Morgenstern um dos precursors da teoria dos jogos moderna: "is often easier to mathematize a false theory than to confront reality". MORGENSTERN, Oskar. Thirteen critical points in contemporary economic theory: an interpretation. Journal of Economic Literature, [s.1.], v. 10, n. 4, pp. 1163-1189, dec. 1972 , p.1169.

105 Essa característica é fundamental para noção de que os agentes ao agirem estão em um processo de aprendizado, aprendendo através das tentativas que podem ser bem-sucedidas ou malsucedidas. Em outras palavras, em um mundo de conhecimento imperfeito os indivíduos estão em constante processo de descobrimento. CACHANOSKY, Nicolás. Spontaneous orders and game theory: a comparative conceptual analysis. Revista de Instituciones, Ideas y Mercados, [s.1.], n 52, pp. 52-88, may. 2010, p. 65-66.

${ }^{106}$ CACHANOSKY, Nicolás. Spontaneous orders and game theory: a comparative conceptual analysis. Revista de Instituciones, Ideas y Mercados, [s.1.], n 52, pp. 52-88, may. 2010, p.62.
} 
uma fundamentação econômica mais sólida e os austríacos com uma linguagem matemática mais sofisticada ${ }^{107}$.

Sob a perspectiva da Escola Austríaca a aplicação da teoria dos jogos para a construção de situações hipotéticas é mais precisa e exata que a neoclássica. De fato, os jogos e modelos desenvolvidos, possuem mais uma função pedagógica e exemplificativa nas mecânicas de competição do que como previsões, podendo ser usadas como ferramentas de estudo do fenômeno econômico.

Portanto, o modelo do dilema dos prisioneiros aplicado ao Direito de Propriedade Intelectual apresentado nesse trabalho tem uma função mais exemplificativa e ilustrativa do que de previsão. Afinal, a simplificação da realidade deve ser empregada de acordo com o caso concreto e apenas como um norte. Em virtude, dos agentes possuírem conhecimentos limitados, serem propensos ao erro na elaboração de suas hipóteses, ignorância quanto a possíveis elementos essenciais e ocultos, além da disparidade entre uma simulação e a realidade.

\section{CONCLUSÃO}

Ante o exposto, o instituto da propriedade intelectual tem como função criar mecanismos eficazes de proteção a atividade criativa. A existência de um market failure na comercialização das expressões do intelecto humano decorre da natureza econômica de bem público. Uma vez que é exposto o conhecimento ao mercado, não há como controlar a circulação da informação. Por essa razão, os criadores concorrem com os copiadores em uma situação de desvantagem, em virtude de que, hipoteticamente, para assimilar a expressão é mais barato do que o investimento em atividades criativas. Nesse cenário, os copiadores estariam em vantagem sobre os criadores causando uma concorrência predatória que desestimularia a inovação tecnológica e a literária artística e científica, no plano macroeconômico.

Em outras palavras, o Direito Intelectual tem como objetivo a criação de um ambiente de equilíbrio no qual os inovadores sejam capazes de explorar comercialmente a suas criações sem serem onerados por atitudes de copiadores não-autorizados. Todavia, o mecanismo heterocompositivo sozinho não é capaz de corrigir a falha de mercado e tampouco é a opção mais barata para os criadores protegerem sua atividade econômica. Por essa razão, o instituto da propriedade intelectual tem

\footnotetext{
107 "Game theory allows the Austrian to come formally to grips with key ideas on subjectivism, coordination, rules and institutions, and the entrepreneurial market process. In particular, the emerging literature on repeated coordination games may be of appeal to Austrians because this literature asks the fundamental questions, such as how diverse players, with differen knowledge and expectations, may eventually home in on a coordinated state".FOSS, Nicolai. Austrian economics and Game Theory: a stocktaking and an evaluation. The Review of Austrian Economics, [s.1.], v. 13, issue 1, pp-41-58, feb. 2000, p. 56-57.
} 
maiores chances de alcançar o equilíbrio quando há possibilidade de contratar e o sistema é minimamente eficaz em garantir uma vantagem na barganha

A concentração desse trabalho foram as patentes, modelos de utilidade e os direitos autorais, e de forma breve os segredos industriais, não sendo analisados as marcas e indicações geográficas. A limitação se dá em razão de que o mesmo fundamento econômico pode ser aplicado aos direitos de patentes e autorais. O problema central abordado foi a indagação quanto a veracidade da função equilibradora do Direito de Propriedade Intelectual. A qual a prima facie foi respondido pela hipótese de que ante os inúmeros fatores subjetivos, a divergência de objetivos, assimetria do conhecimento, desigualdade de recurso e etc., o equilíbrio proposto seria dificilmente alcançado pelo método heterocompositivo sendo exigido o auxílio dos contratos de propriedade intelectual para aproximação de uma competição justa e a devida correção do market failure, sendo proposto o Direito Contratual como ferramenta subsidiária para a política macroeconômica de defensa a atividade inventiva.

Consequentemente, o objetivo geral do artigo foi o emprego da análise econômica do Direito Intelectual e a aplicação do Direito Contratual através da análise econômica de 3 (três) tradições de escolas econômicas: neoclássica, teoria dos jogos e austríaca.

Nesse diapasão, é conclusivo: a função do direito à propriedade intelectual deve concentrar em não só "curar" o market failure como também criar um mercado no qual os criadores possam explorar suas criações através de leis que estimulem a estratégia de cooperação de copiadores e criadores em celebrar acordos de licença. Em outras palavras, a lei de proteção à propriedade intelectual em primeiro lugar deve ser capaz de garantir o desequilíbrio de mercado em favor do inventor e autor e, gradualmente, não gerar óbices a instauração do equilíbrio do mercado em relação àquele invento. Como decorrência da imperfeição do sistema jurídico e da aplicação do instituto, foi demonstrado através do dilema dos prisioneiros que a melhor opção é contratar e que a existência de uma proteção com o potencial de ser efetiva pode levar ao equilíbrio de mercado.

Apesar do modelo do jogo ser uma simplificação, como apontado pelos ensinamentos da Escola Austríaca, é possível aprender com tal modelo que o papel do Direito Intelectual, na prática, não deve ser o controle sobre a expressão, mais o aumento do poder de barganha do criador sobre o copiador com o fim de ser possível a celebração de contratos no qual o criador possa lucrar com sua obra. A natureza disruptiva da atividade criativa exige um foco protetivo sobre a negociação, ao invés da exploração monopolística, e na conduta da boa-fé entre os concorrentes.

Ademais, o foco no Direito Contratual em detrimento de uma abordagem mais radical da assimilação da lógica dos Direitos Reais, pode coadunar melhor com as propostas de penalizar a cópia e incentivar a criação, evitando abusos do Direito de Propriedade Intelectual. 
Portanto, em razão dos motivos expostos, a hipótese supramencionada foi confirmada uma vez que o Direito de Propriedade Intelectual atualmente oferece um mínimo de proteção pelo método heterocompositivo, consequentemente gerando poder de barganha ao criador que, junto com o Direito Contratual e os contratos, é capaz de superar o market failure inerente aos bens econômicos de natureza público e tem a sua disposição instrumentos idôneos para a promoção de um mercado e, na teoria, de repressão a concorrência injusta. Ante a exposição das tradições de pensamento econômico: neoclássico, teoria dos jogos e Escola Austríaca; é possível embasar a hipótese e justificar o papel subsidiário do Direito Contratual como meio eficaz de corrigir a falha de mercado sobre diferentes argumentos que coadunam uníssonos na função de promover o processo de mercado protegendo o desequilíbrio natural e momentâneo da atividade criativa, em primeiro momento, e conduzindo gradualmente ao equilíbrio.

\section{REFERÊNCIAS}

BARBOSA, Denis Borges. Uma introdução a propriedade intelectual. 2 ed. [s.1]:Editora Lumen Juris, 2010.

BARROS, Carla Eugenia Caldas. Manual de Direito da Propriedade Intelectual, Evocati: Aracaju, 2007.

BASSO, Maristela. A tutela constitucional da propriedade intelectual na Carta de 1988: avanço indiscutível. Revista de Informação Legislativa, Brasília, v. 45, n. 179, p. 39-41, jul./set. 2008.

BELL, Tom. Author's welfare: copyright as a statutory mechanism for redistributing rights. Brooklyn Law Review, [s.L.], v. 69, issue 1, pp 229-280, 2003.

BESEN, Stanley M.; RASKIND, Leo J. An introduction to the law and economics of intellectual property. Journal of Economic Perspectives, [s.L.], v. 5, nº 1, p.3-27, winter 1991.

CABELLO, Andrea Felippe; PÓBOA, Luciano Martins Costa. Análise econômica da primeira Lei de Patenttes brasileiras. Estud. Econ., São Paulo, v. 46, n. 4, p. 870-907, dec. 2016.

CACHANOSKY, Nicolás. Spontaneous orders and game theory: a comparative conceptual analysis. Revista de Instituciones, Ideas y Mercados, [s.1.], n 52, pp. 52-88, may. 2010.

CARRARO, André. Propriedade Intelectual e Teoria dos Jogos. $1^{\text {a }}$ ed. Santa Cruz do Sul: EDUNISC, 2005.

CINTRA, Antônio Carlos de Araújo; GRINOVER, Ada Pellegrini; DINAMARCO, Cândido Rangel. Teoria geral do processo. 29. ed. São Paulo: Malheiros, 2007.

COOTER, Robert; ULEN, Thomas. Law and economics. $6^{\text {th }}$ ed. Berkeley: Berkeley Law Books, 2016. Disponível em: scholarship.law.berkeley.edu/books/2. Acesso em: 12 out 2018 
CZELUSNIAK, Vivian Amaro; RIBEIRO, Marcia Carla Pereira. Cooperação para Efetividade dos Contratos de Transferência de Tecnologia: uma análise juseconômica. Economic Analysis of Law Review, Brasília, v. 4, nº1,p. 21-34, Jan./jun. 2013.

DEAZLEY, Ronan; KRETSCHMER, Martin; BENTLY, Lionel. Privilege and Property: Essays on the history of copyright.Cambridge OpenBook Publishers: 2010.

FARBER, Daniel A. Contract Law and Modern Economic Theory. Northwestern University Law Review, [s.1.], v. 78, n. 2, pp. 303-339, jan. 1983.

FACHIN, Luiz Edson. Novo conceito de ato e negócio jurídico. Curitiba: Educa, Scientia et Labor, 1988.

FOSS, Nicolai. Austrian economics and Game Theory: a stocktaking and an evaluation. The Review of Austrian Economics, [s.1.], v. 13, issue 1, pp-41-58, feb. 2000.

GORDON, Wendey J. Asemetric market failure and prisioner's dilemma in intellectual property. University of Dayton Law Review, [s.1.], vol. 17, no 3, pp. 853-869, may. 1992.

GOMES, Luiz Flávio; SILVA, Marcelo Rodrigues da. Criminalidade organizada e justiça penal negociada: delação premiada. Revista de Filosofia do Direito, do Estado e da Sociedade, Natal, v. 6, n. 1, pp. 164-175, jan./jun., 2015, p.172.

HAYEK, Friedrich A. Individualism \& Economic Order. 3 ed. Chicago: The University of Chicago Press, 1958.

HOPPE, Hans-Hermann. A theory of socialism and capitalism. Boston: Kluwer Academic Publishers, 1989.

IORIO, Ubiratan Jorge. Ação, tempo e conhecimento: A Escola Austríaca de economia. São Paulo: Instituto Ludwig von Mises, 2011

JOLLS, Christine; SUNSTEIN, Cass R.; THALER, Richard. A behavioral approach to law and economics. Stanford Law Review, [s.1.], pp. 1471-1550, may. 1998.

KELLY, Yvan J. Mises, Morgenstern, Hoselitz, and Nash: the austrian connection to early game theory. The Quartly Journal of Austrian Economics, [s.1.], v. 12, n 3, pp 37-42, 2009.

KINSELLA, Stephan. Against Intellectual Property. Journal of Libertarian Studies, v. 15, n. 2, pp. $1-55,2001$.

KIRZNER, Israel M. Competição e atividade empresarial. São Paulo: Instituto Ludwig von Mises, 2012

KOSTYLO, Joanna. From gunpowder to print: the common origins of copyright and patent. In: DEAZLEY, Ronan; KRETSCHMER, Martin; BENTLY, Lionel. Privilege and Property: Essays on the history of copyright. Cambridge OpenBook Publishers: 2010.

LANDES, William M.; POSNER, Richard A. The political economy of intellectual property law. Washington D.C.: AEI-Brookings Joint Center for Regulatory Studies, 2004. 
LEMLEY, Mark A. Property, Intellectual Property, and Free Riding. Texas Law Review, [s.1.], vol. 83, issue 291, 2004.

LEMLEY, Mark A. Ex Ante versus Ex Post Justifications for Intellectual Property. The University of Chicago Law Review, [s.1.], vol 71, issue 129, pp 129-149, 2004.

MELLO, Maria Tereza Leopardi. Propriedade Intelectual e Concorrência. Revista Brasileira de Inovação, Rio de Janeiro, v. 8, nº 2, p. 371-402, julho/dezembro 2009.

MISES, Ludwig von. Liberalism: in the classical tradition. 3 ed. Auborn: Mises Institute, 2000, p. $37 . \quad$ Disponível em: https://misesmedia.s3.amazonaws.com/Liberalism $\% 20 \mathrm{In} \% 20$ the $\% 20$ Classical\%20Tradition_3.pdf?file=1\&type $=$ documen . Acesso em: 13 set 2018 .

MISES, Ludwig Von. Ação humana: um tratado de economia. 3.1 ed. São Paulo: Instituto Ludwig von Mises Brasil, 2010

MORGENSTERN, Oskar. Thirteen critical points in contemporary economic theory: an interpretation. Journal of Economic Literature, [s.1.], v. 10, n. 4, pp. 1163-1189, dec. 1972.

OSBORNE, Martin J. An introduction to Game Theory. Toronto: Oxford University Press, 2000.

PICKER, Randal C. An introduction to game theory and the law. Coase-Sandor Institute for Law \& Economics, [s.1.], n. 22, pp. 2-20, 1994.

PIMENTEL, Luiz Otávio. O acordo sobre os aspectos dos direitos de propriedade intelectual relacionados com o comércio. Seqüência: Estudos Jurídicos e Políticos, Florianópolis, p. 167-196, jan. 2002, p.169. ISSN 2177-7055. Disponível em: https://periodicos.ufsc.br/index.php/sequencia/article/view/15338. Acesso em: 08 set. 2018.

PLANT, Arnold. The economic theory concerning patents for inventions. In: PLANT, Arnold. Selected economic essays and addresses. London: Routledge \& Kegan Paul, 1974.

POSNER, Richard. Intellectual Property: The Law and Economics Approach. Journal of Economic Perspectives, [s.1.], vol 19, n 2, pp-57-73, spring 2005.

ROTHBARD, Murray N. Man, Economy, and State: a treatise on economic principles with Power and Market government and the economy. 2. ed. Auburn: Ludwig von Mises Institute, 2009

SÁ FILHO, Fábio Menezes de. Análise da Admissibilidade da Resolução de Conflitos Individuais Afetos ao Direito Laboral Desportivo pela Arbitragem no Brasil. In: Melo Filho, Álvaro; SÁ FILHO, Fábio Menezes de; SOUZA NETO, Fernando Tasso de; RAMOS, Rafael Texeira (Coord). Direito do Trabalho Desportivo - Homenagem ao Professor Albino Mendes Baptista. Recife: Quartier Latin, 2012.

SARLET, Ingo Wolfgang. Os direitos fundamentais sociais como "cláusulas pétreas". Caderno de Direito, Piracicaba, v. 3, n. 5, p.78-97, jul./dez. 2003.

SILVA, Luciana Aboim Machado Gonçalves da; VITALE, Carla Maria Franco Lameira. Aplicação da teoria dos jogos na mediação de conflitos: o equilíbrio de nash como estratégia de maximização de ganhos. Revista de Formas Consensuais de Solução de Conflitos, [s.1.], v.2, n.1, pp. 124-139, 2016. 
SOUZA, Ananda Portes; TEXEIRA, Andre Costa Ferreira de Belfort. A teoria dos jogos e o direito: entendendo a aplicabilidade da teoria dos jogos ao direito a partir dos jogos de gun jumping e de investimento em propriedade intelectual. Revista de Direito, Inovação, Propriedade Intelectual e Concorrência, Minas Gerais, v. 1, n.2, pp. 21-41, jul/dez. 2015.

TIMM, Luciano Benetti; CAOVILLA, Renato. As teorias rivais sobre a propriedade intelectual no Brasil. Berkeley: Berkley Program in Law and Economics, 2009, p. 7. Disponível em: https://escholarship.org/uc/item/3fs9d0m3\#main. Acesso em: 12 out 2018.

ZANINI. Leonardo Estevam de Assis. O Estatuto da Rainha Ana: estudos em comemoração dos 300 anos da primeira lei de copyright. Revista do Tribunal Regional Federal da $1^{\text {a }}$ Região, Brasília, v. 22 , n. 9 , out. 2010 . 